\title{
A DESINFECÇÃO DE NEBULIZADORES EM UMA UNIDADE BÁSICA DE SAÚDE DE RIBEIRÃO PRETO
}

\author{
Michele Benevenuto Balthazar* \\ Branca Maria de Oliveira Santos**
}

BALTHAZAR, M.B.; SANTOS, B.M. de O. A Desinfecçăo de nebulizadores em uma unidade básica de saúde de Ribeirão Preto. Rev.Esc.Enf.USP, v.31, n.1, p.23-35, dez. 1997.

Diante da grande divergência do pessoal de enfermagem em relação à desinfeç̧ão de nebulizadores em Unidades Básicas de Saúde (UBS), da falta de padronização do uso de produtos químicos e do processo de desinfecção como um todo, as autoras decidiram proceder a uma investigação cujos objetivos foram: observar sistematicamente a operação de rotina de desinfeção dos nebulizadores na sala de aerossóis de uma UBS e detectar, apontar e alertar para as possíveis falhas do processo de desinfecção. Para tanto realizou-se a observação direta sistematizada do processo de desinfeç̧ão e a aplicação de um questionário junto à enfermeira responsável pelo serviço. Os resultados mostraram que o processo de desinfeçãa realizado não está de acordo com as normas preconizadas pelo Ministério da Saúde e/ou Secretaria de Estado da Saúde; revelam ainda uma deficiência de conhecimento do pessoal envolvido com esta atividade quanto à padronização do uso dos produtos químicos utilizados e condições que interferem na ação dos mesmos durante o processo de desinfecção. Acredita-se que os resultados obtidos apontem para a necessidade de padronização do processo de desinfecção como um todo, segundo as normas sanitárias vigentes e de educação continuada em serviço, visando a qualidade da assistência de enfermagem prestada aos usuários do serviço de saúde.

UNITERMOS: Desinfeção de nebulizadores. Rotina de desinfecção em UBS.

\section{1 - INTRODUÇÃO}

As doenças causadas por infecção representam importantes problemas de saúde e con tinuam sendo um desafio para a equipe responsável pela sua prevenção e controle.

A infecção tem sido considerada quando ocorre a penetração de um agente seguida de desenvolvimento e/ou multiplicação no interior dos órgãos e tecidos,

* Aluna de Graduação em Enfermagem da EERP-USP, Bolsista do Programa Especial de Treinamento CAPES

** Professora Doutora do Departamento de Enfermagem Geral e Especializada da EERP. USP - Orientadora. 
daí podendo ou não resultảr em sintomatologia aparente ${ }^{7}$. De maneira geral, os agentes envolvidos são microrganismos unicelulares que têm a capacidade de instalar-se no organismo, desempenhando, dessa forma, o papel de agente etiológico na infecção resultante.

A penetração, desenvolvimento e/ou multiplicação de um agente infeccioso pode se dar por diversas maneiras, sendo uma delas representada por artigos contaminados - os fômites. Estes são constituídos por quaisquer artefatos que tenham recebido a carga infectante e que possam transferíla ao novo hospedeiro, quando por este utilizados. Assim, alguns artigos ou materiais hospitalares podem desempenhar um importante papel na veiculação desses agentes.

Os artigos têm sido classificados, de acordo com o risco potencial de transmissão de infecção, em críticos - aqueles que vão penetrar nos tecidos subepiteliais, no sistema vascular e em outros órgãos isentos de flora microbiana própria, semi-críticos - aqueles que entram em contato com a pele não íntegra ou com mucosas íntegras e não críticos, os que entram em contato apenas com a pele íntegra e os que não entram em contato com o indivíduos ${ }^{2,3,4,10}$. Esta classificação é que tem norteado as recomendações de medidas de prevenção e controle das doenças infecciosas baseadas, primariamente, no isolamento e nos meios de esterilização e desinfecção.

Enquanto a esterilização é in dicada para os artigos críticos, a desinfecção, como processo de destruição de microrganismos patogênicos ou não, na forma vegetafiva, é indicada para os artigos semi-crificos, com o objefivo de evitar que a próxima pessoa a utilizar o material seja contaminada, proporcionando desse modo, segurança ao usuário ${ }^{3,10}$.

A desinfecção pode ser obtida mediante processo físico, através da exposição do artigo em água fervente por 30 minutos, ou processo químico, pela imersão total do artigo em produto químico apropriado, também por 30 minutos, exigindose que, posteriormente a este período, o material seja enxaguado em água corrrente e, após a secagem, acondicionado e guardado para uso. Para ser submetido a qualquer um dos dois processos, o material deve estar limpo e seco $0^{2,10}$.

A efetividade do primeiro método, o físico, so é obtida quando o artigo a ser desinfetado suporta a ação da água em ebulição durante o tempo de exposição recomendado. No caso de determinados artigos que não são compatíveis com esse método, pela sensibilidade ao calor, os mesmos devem ser submetidos à desinfecção pelo segundo método, o químico ${ }^{2}$. Diante dessas considerações, o método de desinfecção de artigos semi-críticos varia, portanto, com a natureza dos mesmos.

Dentre os artigos que devem ser submetidos à desinfecção química, pelos motivos acima citados, estão os nebulizadores*, equipamentos destinados a

* Neste trabalho, o termo nebulizadores estará indicando equipamentos de nebulização simples (conjunto-copo acoplado à máscara de aerossol). Não foi considerada a extensão plástica que é conectada ao ar comprimido. 
introduzir líquidos, sob forma de aerosol, no trato respiratório do paciente ${ }^{3,12,14}$. O processo terapêutico dos nebulizadores consiste em distribuir uma suspensão de partículas de água nas vias aéreas, partículas estas que variam em sua dimensão de 0,5 a 5 micras em nebulizadores mecânicos simples, em oxigênio ou ar comprimido, com ou sem associação de medicação, para alívio de processos inflamatórios, congestivos e obstrutivos.

A utilização de nebulizadores que não atendam aos princípios preconizados para o processo de desinfecção, pode produzir aeross6is contaminados ${ }^{3,12,14}$, seja por microrganismos de pacientes que já utilizaram o equipamento ou por crescimento bacteriano nas soluções empregadas ${ }^{11}$. Essa contaminação ocorre por inoculação de microrganismos contaminantes diretamente nos pulmões do paciente uma vez que os aeross6is produzidos são suficientemente pequenos para ultrapassar a barreira mucociliar do trato respiratório superior e atingir os alvéolos pulmonares, podendo causar pneumonia necrosante por bastonetes gram negativos ${ }^{13,14}$.

Os produtos recomendados para a desinfecção dos nebulizadores são os fenóis sintéticos, o glutaraldeído a $2 \%$ e o hipoclorito de sódio a $0,5 \%$, todos por um período de 30 minutos, com imersão total do artigo ${ }^{2,3,10,12,14}$

A efetividade do processo de desinfecção do material requer do pessoal envolvido com esta atividade, conhecimentos quanto às condições que interferem na ação dos produtos químicos, à padronização do uso e às normas de aquisição dos mesmos ${ }^{10}$. Ainda que tais conhecimentos estejam bem definidos na literatura, na prática observa-se uma grande divergência quanto à utilização dos princípios para eles estabelecidos. A desinfecção de nebulizadores não foge a esta realidade, pois se observa que o pessoal responsável por esta atividade não tem atendido aos princípios recomendados, colocando em dúvida, a eficácia do processo.

Considerando o fato de que as Unidades Básicas de Saúde, enquanto porta de entrada do sistema de saúde, devem prestar atendimento integral preventivo e curativo a todos os indivíduos previdenciários ou não5 e que as mesmas têm sido um dos serviços mais procurados pela população para sanar, dentre outros, os problemas respiratórios, que comumente têm implicado em tratamento através de aerossolterapia, com o uso de nebulizadores, julgou-se procedente realizar a presente investigação com o propósito de:

- observar sistematicamente a operação de rotina de desinfecção dos nebulizadores na sala de aerossóis de uma Unidade Básica de Saúde;

- levantar o conhecimento da enfermeira responsável pelo serviço a respeito da rotina de desinfecção;

- detectar, apontar e alertar para as possiveis falhas no processo de desinfecção dos nebulizadores. 


\section{2 - METODOLOGIA}

\subsection{Caracterização da sala de aerossóis}

Uma Unidade Básica Distrital de Saúde de Ribeirão Preto foi a escolhida para este estudo. O critério de escolha foi baseado no fato da referida Unidade servir de campo de estágio para alunos de graduação em enfermagem despertando assim nosso interesse em desenvolver os objetivos propostos. Além disso, a UBS apresenta em sua estrutura física uma sala destinada especialmente à aerossolterapia, com aproximadamente $7 \times 2 \mathrm{~m}^{2}$, paredes azulejadas e iluminação adequada. Em duas das paredes existem 10 saídas para ar comprimido, sendo que apenas 6 são efetivamente utilizadas e um banco fixo para acomodar os usuários do serviço. Possui também uma pia para o processamento dos materiais utilizados no local.

Os nebulizadores prontos para o uso diário são colocados sobre uma das laterais da pia, protegidos por um lençol limpo. Na extremidade oposta há um balde plástico identificado com data e assinatura, contendo a solução desinfetante. O mesmo é coberto com uma tampa retangular plástica que não veda toda a sua superfície.

A aerossolterapia é da responsabilidade do pessoal de enfermagem que também responde pela sala de medicação. Esse pessoal não possui escala fixa e obedece a uma rotatividade programada.

Os usuários do serviço geralmente são pacientes pertencentes à área atendida pela própria Unidade, ainda que possam ser encaminhados por outras unidades básicas ou hospitalares.

\subsection{Instrumentos de coleta de dados}

Para a coleta de dados foi realizada, num primeiro momento, a observação direta sistematizada do funcionamento da sala, priorizando o processo de desinfecção dos nebulizadores utilizados na sala de aerossóis. A observação foi realizada durante uma semana, em períodos alternados (manhã e tarde), levandose em consideração o fato de que o pessoal de enfermagem que atua na referida sala obedece a uma rotatividade programada.

A observação tem papel fundamental em todas as fases da pesquisa, porém na coleta de dados esse papel torna-se ainda mais evidente ${ }^{8}$. Constitui-se em elemento básico da investigação científica, pois possibilita a identificação e a obtenção de provas à respeito de objetivos sobre os quais os indivíduos não tem consciência, mas que orientam seu comportamento9. O principal inconveniente da observação está em que a presença do pesquisador pode provocar alterações no comportamento dos observados, destruindo a espontaneidade dos mesmos e produzindo resultados pouco confiáveis ${ }^{8}$. 
Na tentativa de atender a essas considerações, a observação realizada neste estudo foi identificada como um estágio voluntário, não sendo revelado aos funcionários que a mesma objetivava conhecer como ocorria o processo de desinfecção dos nebulizadores. Foi desenvolvida de modo a procurar atender basicamente os mesmos ítens contidos no questionário, aplicado num segundo momento.

O questionário é um dos instrumentos mais usados para levantamento de informações e obtenção de dados da realidade ${ }^{1}$.O modelo utilizado, (ANEXO I) foi aplicado a uma das enfermeiras responsáveis pelo serviço de enfermagem da UBS, que se encontrava presente na ocasião. Foram feitas oito questões abertas relativas ao processo de desinfecção a que são submetidos os nebulizadores e uma questão final que permitia à entrevistada fazer observações gerais. Para comprovar sua validade, o instrumento foi submetido à apreciação de um juiz, docente da Escola de Enfermagem de Ribeirão Preto-USP, que julgou a pertinência dos ítens, a clareza e a objetividade da linguagem utilizada. As questões propostas inicialmente foram preservadas, porém sofreram algumas alterações quanto à clareza, complementação e grafia, conforme as sugestões recebidas.

\section{3 - RESULTADOS}

\subsection{Considerações iniciais}

Para a exposição, a análise e a discussão dos resultados procurou-se agrupar o conteúdo obtido através do questionário aplicado segundo os ítens abaixo relacionados, confrontando-os com a observação realizada e com os princípios recomendados pela literatura. Foram utilizadas basicamente as recomendações do Ministério da Saúde e da Secretaria de Estado da Saúde ${ }^{2,3,4,10,14}$.

\subsubsection{Tratamento Prévio}

Não foi verificado durante a observação nenhum tratamento que antecedesse o processo de desinfecção final dos nebulizadores. A resposta obtida pelo questionário coincidiu com a observação, confirmando o fato observado. Pôdese detectar ainda, pela observação, que algumas vezes os nebulizadores foram mergulhados diretamente no desinfetante, ainda contendo restos de medicação (soro fisiologico, broncodilatadores). Esta prática resulta na diluição do desinfetante e na consequente perda de sua efetividade.

Segundo o preconizado na literatura, qualquer material antes de ser submetido à desinfecção final, ou seja, ao processo de destruição de microrganismos patogênicos ou não, na forma vegetativa, deverá estar totalmente limpo e seco. A limpeza tem por objetivo remover toda a matéria orgânica que protege os microrganismos contaminantes do contato indispensável com o agente 
desinfetante. Consiste na lavagem, que pode ser feita com sabões, detergentes ou soluções desincrostantes, e secagem do material, após a desinfecção prévia. A desinfecção prévia é necessária para proteger as pessoas que irão proceder à limpeza dos artigos e pode ser efetuada imergindo os mesmos em produto químico apropriado, por um período de 30 minutos. Independentemente do processo de desinfecção a que venha a ser submetido, após o uso todo artigo deverá ser considerado "contaminado", qualquer que seja o grau de sujidade presente. Desta forma, a desinfecção prévia é recomendada. No entanto, em algumas circunstâncias essa desinfecção prévia poderá esbarrar em dificuldades operacionais, como no caso de Unidades que apresentam grande rotatividade de usuários, o que acarreta a necessidade de maior agilidade no processo de desinfecção. Nesses casos, para assegurar a proteção de quem realiza a limpeza, o uso de equipamentos de proteção individual (EPIs) é recomendado ${ }^{4,10,14}$.

\subsubsection{Desinfeccão Final}

Para oferecer segurança ao usuário quando da realização da aerossolterapia e para evitar que o mesmo seja contaminado pelo material durante a sua execução, faz-se necessário um correto procedimento de desinfecção final. Para isso pontos importantes devem ser considerados:

\section{Recipiente}

Tem sido preconizado para a desinfecçã $0^{4,10,14}$ o uso de um recipiente de plástico rígido, considerando o poder oxidante das soluções desinfetantes, sendo contra indicado a utilização de recipiente metálico. A capacidade do recipiente deve atender à quantidade de material a ser processado de modo que o mesmo permaneça totalmente submerso na solução. $O$ recipiente deve conter ainda uma tampa que vede toda a superfície do balde para evitar a volatilização do produto químico e conseqüentemente, o comprometimento da desinfecção.

Observou-se que o recipiente utilizado na Unidade em questão não está totalmente de acordo com as normas recomendadas. É constituído de um balde plástico de 5 litros com tampa retangular que não veda a superfície do mesmo, contradizendo a informação obtida pelo questionário de que toda a superfície do recepiente é vedada.

Por outro lado, foi observado também que a capacidade do recipiente não era suficiente para conter todos os nebulizadores a serem processados, uma vez que o número excessivo destes não possibilitava a imersão total dos mesmos na solução.

\section{Produto}

O produto químico utilizado pela Unidade Básica deste estudo, o Glataraldeído a $2 \%$, está enquadrado em um dos grupos de uso corrente preconizados. Segundo a informaçãó do questionário, a validade do Glataraldeido, após sua ativação, é de 14 dias quando a sua concentração é de $1 \%$ e de 28 dias 
quando a concen tração é de $2 \%$. Pelo tempo de observação não foi possivel verificar se essa recomendação (14 ou 28 dias) era atendida. O que foi observado é que havia uma identificação no recipiente com a data de ativação do produto e a assinatura do responsável e que o mesmo era utilizado apenas para desinfecção de nebulizadores. Convém ressaltar que o tempo de validade do Glutaraldeído varia de acordo com o $\mathrm{pH}$ e não de acordo com a concentração, uma vez que a solução em pH de 8,5, polimeríza-se em 14 dias e em $\mathrm{pH} 7,5$, polimeríza-se em 28 $\operatorname{dias}^{4,10}$.

Outros produtos têm sido recomendados ainda para essa finalidade, tais como o Hipoclorito de S6́dio e os Fenóis Sintéticos ${ }^{3,10}$. O Hipoclorito de S6́dio tem sido indicado e bastante utilizado na desinfeç̧ão de artigos semi-críticos por apresentar vantagens tais como menor custo, baixa toxicidade, fácil manuseio e ampla ação antimicrobiana. A concentração indicada para nebulizadores tem sido de $0,5 \%(5000 \mathrm{ppm})$ de cloro ativo, por 30 minutos $^{10}$. Os Fenóis também têm sido recomendados exclusivamente comó desinfetantes, porém não têm sido muito utilizados para desinfeç̧ão de nebulizadores, tendo em vista o seu efeito deletério sobre $o$ artigo a ser desinfetado ${ }^{10}$.

Convém ressaltar, no entanto, o fato observado e descrito anteriormente de que os nebulizadores a serem processados eram colocados na solução desinfetante sem tratamento prévio e muitas vezes com restos de medicação, o que poderia contribuir para a alteração da composição do produto.

\section{Tempo}

O material a ser desinfetado deve estar totalmente submerso no desinfetante durante um periodo de 30 minutos ${ }^{3,410,14}$. Os horários de início e término do processo devem, portanto, ser controlados.

Foi observado que não havia registro de controle dos horários de início e término do processo de desinfecção, ainda que a resposta obtida pelo questionário afirmasse existir uma folha para controle de tempo, com assinatura do funcionário. Entretanto, essa folha foi encontrada apenas uma vez em um dos periodos de observação, e mesmo nessa ocasião a mesma não estava sendo utilizada conforme o informado. O questionário fazia referência também ao fato de que a permanência do material no desinfetante deve ser de 30 minutos. $O$ observado foi que os nebulizadores eram mergulhados na solução à medida que cada nebulização acabava, não sendo possível distinguir aquele que era imerso primeiro daquele que era imerso por último.

Pela descrição acima evidencia-se a possibilidade de alguns nebulizadores permanecerem na solução desinfetante mais e outros menos que o tempo recomendado, ocorrendo novamente comprometimento da desinfeç̧ão.

\section{Enxágüe}

A resposta obtida pelo questionário mostrou que os nebulizadores eram colocados e retirados da solução desinfetante com auxílio de uma pinça e que, 
após serem retirados do produto químico, os mesmos eram apenas secos sobre um lençol limpo. Porém, pela observação pode ser verificado que, após retirados da solução desinfetante com auxílio de pinça, os nebulizadores eram colocados na cuba inoxidável da pia para serem lavados com água corrente e detergente comum. Essa prática possibilita nova contaminação dos nebulizadores ao entrarem em contato com a cuba, considerando a finalidade da mesma, prejudicando assim a ação biocida do desinfetante.

Recomenda-se que os nebulizadores sejam apenas enxaguados abundantemente em água corrente, após passarem pela desinfecção final. Dispensa-se nesta fase, o uso de detergentes, uma vez que a matéria orgânica do material já foi removida na limpeza prévia. Além disso, a água abundante é capaz de deixar o material livre dos resíduos tóxicos deixados pelo desinfetante.

\section{$\underline{3.1 .3}$ Acondicionamento}

Segundo informação do questionário, os nebulizadores não eram acondicionados após o processo de desinfecção. De fato, como já relatado anteriormente, o material permanecia sobre a pia protegido por um lençol limpo, pronto para novo uso.

Quando não é possível o acondicionamento individual do material, recomenda-se que o mesmo seja guardado em recipiente com tampa, esterilizado ou desinfetado diariamente, específico para esse fim. O material poderá ser acondicionado ainda em local limpo e livre de poeira, sendo proibido o acondicionamento em áreas próximas às pias ${ }^{4,10}$.

\subsubsection{Padronizacão do Processo}

A resposta obtida pelo questionário foi afirmativa quando se questionou a existência de padronização do processo de desinfecção. A padronização preconizada era de que apenas um auxiliar colocasse e retirasse as máscaras da desinfecção para controle do tempo e que havia uma folha com a assinatura daquele encarregado da execução do procedimento.

A padronização pode ser definida como a uniformização dos comportamentos dos indivíduos, segundo modelos aceitos por um grupo ou impostos pela criação de novos hábitos ${ }^{6}$. À luz dessa definição pode-se perceber pela informação do questionário que a padronização era atendida apenas no que se referia ao fato de que um único funcionário colocava e retirava os nebulizadores da desinfecção. No entanto, convém reconsiderar que na prática isso não foi observado, visto que não era o mesmo funcionário que se encarregava deste procedimento e que cada um realizava a desinfecção segundo seus próprios princípios, sem preenchimento correto da folha de assinaturas. Parece oportuno referir aqui que, segundo o questionário, as orientações para efetuar a desinfecção eram "trocadas" entre os próprios funcionários.

Ao se questionar sobre a utilização pela instituição de uma norma ou critério 
que direcionasse o processamento, a realização e a avaliação do procedimento de desinfecção dos nebulizadores, não foi obtida resposta.

Esse quadro vem corroborar o que o subgrupo-tarefa de "Esterilização de Materiais" do Grupo de Coordenação para Assuntos de Enfermagem do CADAIS* obteve por meio de um levantamento das condições de esterilização de materiais na rede pública, cujos resultados permitiram ao grupo concluir que falta às Unidades de Saúde um padrão mínimo de desempenho nos procedimentos de desinfecção e esterilizaçã̃o ${ }^{10}$.

A título de informação, convém ressaltar o não preenchimento da última questão do questionário que permitia à enfermeira se manifestar sobre qualquer observação.

\section{4 - CONSIDERAÇÕES FINAIS}

Ao se pretender conhecer a operação de rotina de desinfecção de nebulizadores de uma Unidade Básica de Saúde, com o intuito de detectar as possíveis falhas no processo, verificou-se pelos resultados encontrados, que a mesma não atende às recomendações preconizadas pelas normas vigentes na literatura atual especifica ${ }^{2,3,4,10,14}$.

Pôde-se observar uma dicotomia entre as informações obtidas pelas respostas do questionário e a observação direta realizada, evidenciando uma ausência de padronização,

Foram detectadas falhas no processo como um todo, desde o recipiente, produto, tempo, enxagüe até $o$ acondicicnamento dos nebulizadores processados. Essas falhas provavelmente acarretam um produto final com pouca confiabilidade do ponto de vista da desinfecção, não oferecendo, conseqüentemente, segurança ao usuário.

É importante considerar nesse contexto, a figura do enfermeiro como profissional responsável pela garantia da qualidade de assistência de enfermagem prestada em sua Unidade, tendo de um lado seu compromisso profissional e, de outro, os obstáculos e as expectativas da própria Unidade, enquanto instituição pública. Isso implica na necessidade de adequar o seu saber dentro do fazer, através de soluções alternativas viáveis e passíveis de avaliação e o compromisso com a supervisão das atividades realizadas pelo seu pessoal. Essas atividades constituir-se-ão em um indicador das necessidades de orientação, atualização e reciclagem dos envolvidos com a assistência de enfermagem ao paciente, a fím de permitir em tempo hábil, a adoção de medidas corretivas.

* Centro de Apoio ao Desenvolvimento de Assistencia Integral à Saúde, da Secretaria de Estado da Saúde de São Paulo. 
No que se refere ao processo de desinfecção de nebulizadores, essa supervisão e educação devem se constituir em um instrumento de avaliação resultante de uma observação atenta do emprego da técnica de desinfecção utilizada, seguida de medidas de intervenção e providências necessárias para garantir um material que atenda um padrão mínimo de qualidade no que se relaciona a esse procedimento.

\section{REFERÊNCIAS BIBLIOGRÁFICAS}

01- BARROS, A.J.B.; LEHFELD, N.A.S. Fundamentos da metodologia. São Paulo, Mc Graw Hill, 1986. p.109-110: A pesquisa científica.

02- BRASIL. Leis, etc.. Portaria n 930 de 27 de agosto de 1992. Diário Oficial da União, Brasília, 04 de setembro de 1992, Seçăo 1, p.12.279-12.281.

03- BRASIL. Ministério da Saúde. Centro de Documentação do Ministério da Saúde. Manual de controle de infeç̧ão hospitalar. Brasília, 1985.p.55-58 (S6́rie A, n-16).

04- BRASIL. Ministério da Saúde. Coordenação de Controle de Infecção Hospitalar. Processamento de artigos e superfícies em estabelecimentos de saúde. Brasília, 1993. p.8, 9-18.

05- COMISSÃO INTERINSTITUCIONAL MUNICIPAL DE SAÚDE. Secretaria técnica. Proposta de reestruturacão de unidades de saúde. Ribeirāo Preto, CIMS, 1986. (Mimeografado).

06- FERREIRA, A.B.H. Novo dicionário de línqua portuguesa. $2^{a}$ ed. Rio de Janeiro, Nova Fronteira, 1986.p.1245: padronização.

07- FORATINI,O.P. Epidemiologia geral. São Paulo, Artes Médicas, 1986.p.192: As doenças transmissíveis.

08- GIL, A.C. Métodos e técnicas de pesquisa social. São Paulo, Atlas, 1987.p.104-111: observação.

09- MARCONI, M.A.; LAKATOS, E.M. Técnicas de pesquisa. São Paulo, Atlas, 1986. p.65-68: observaçăo.

10- SÃo PAULO (Estado). Secretaria de Estado da Saúde. Centro de Apoio ao Desenvolvimento de Assistência Integral à Saúde. Organização do centro de material e nocōes de esterilizacão. São Paulo, CADAIS, 1993. p.14-55.

11- SCHIMITZ, E.M.R. A Enfermagem em pediatria e puericultura. Rio de Janeiro, Atheneu, 1989. p.311-313: Inaloterapia: fundamentos para atuação da enfermagem pediátrica. 
12- ZANON,V. Esterilizaçăo, desinfecção e anti-sepsia. In: FERRAZ, E.M. Manual de controle de infeccão em cirurgia. Såo Paulo, Pedagógica e Universitária, 1982. p.305-306, 310.

13- ZANON,V. et. al. Infecçס̃es hospitalares na unidade de tratamento intensivo.

In: NEVES, J. Infecçতes hospitalares: prevenção, diagnóstico e tratamento. Rio de Janeiro, Médica e Científica, 1987, p.745.

14- ZANN,V.; PEREIRA, A.Z. Desinfecção e limpeza. In: ; NEVES, J. Infecções hospitalares: prevenção, diagnóstico e tratamento. Rio de Janeiro, Médica e Científica, 1987. p.879-880.

\author{
ANEXO I \\ QUESTIONÁRIO PARA COLETA DE DADOS
}

\author{
UNIVERSIDADE DE SÃO PAULO \\ ESCOLA DE ENFERMAGEM DE RIBEIRÃO PRETO
}

\title{
INSTRUÇÃO
}

Estamos realizando uma pesquisa com o propósito de verificar como se dá a desinfecção do material utilizado na sala de aerossóis, especificamente máscaras para aerossóiss, desta Unidade Básica de Saúde.

Para tanto solicitamos sua colaboração no sentido de responder, sem censura, às questões propostas neste questionário, comprometendo-nos a manter as mesmas em sigilo, não havendo necessidade de identificação de sua pessoa.

Sua contribuição será importante pois nos fornecerá informações para uma melhor compreensão do processo de desinfeç̧̃o realizado no serviço de aerossóis, e subsídios para nossa pesquisa. Por favor não deixe nenhuma questão sem resposta.

Esperando contar com seu apoio e colaboração, agradecemos antecipadamente. 


\section{Questionário}

1- Às máscaras utilizadas para realização dos aerossóis recebem algum tratamento antes do processo de desinfeç̧ão? Em caso afirmativo, descreva-o.

2. Quanto à desinfecção química das máscaras:

2.1. Qual o produto químico utilizado?

2.2. Qual a concentração utilizada?

2.3. Qual o recipiente usado para conter o produto químico durante a desinfecção? Especifique $\cdot$ material que constitue o recipiente, e se tem tampa ou não.

2.4. Por quanto tempo as máscaras ficam imersas no produto químico?

3- Após a desinfecção química as máscaras recebem algum outro tratamento para serem acondicionadas? Em caso afirmativo, descreva-o.

4- Descreva a seqüência do processo de desinfecção química das máscaras realizado na Unidade.

5- Nesta Unidade, há uma padronização desse processo de desinfecção química das máscaras de aerossóis? Em caso afirmativo, quais normas ou critérios são utilizados?

6- Qual o período de validade do produto químico uülizado, após seu preparo?

7- Como e onde as máscaras são acondicionadas antes de serem reutilizadas?

8- Os funcionários que realizam a desinfecção das máscaras recebem alguma orientação prévia para efetuá-la? Em caso afirmativo, quem fornece essas orientações?

9- Observações do profissional ${ }^{3}$.

$3 \quad$ O verso das folhas poderá ser utilizado como espaço para respostas. 
BALTHAZAR, M.B.; SANTOS, B.M. de O. Nebulizer Disinfection in Ribeirăo Preto Health Units Rev.Esc.Enf.USP, v.31, n.1 p. 23-35, apr. 1997.

Considering the widely divergent views of the nursing staff with respect to nebulizer disinfecfion in Basic Health Units (BHU) and to the lack of standardizafion of the use of chemical products and of the disinfection process as a whole, the author undertook an investigafion with the folowing objectives: to observe systematically the routine procedure of nebulizer disinfection in the aerosol room of a BHU, and to detect, point out and wam about possible faults in the disinfecfion process. The disinfection process was observed directly and systemafically and a quesfionnaire with open questions was applied to the nurse responsible for the service. The results showed that the process of disinfecfion performed is not consistent with recommendations by the Health Departament and/or State Health Secretariat, and that the personnel involved in this acfivity has incomplete knowledge of the standardizafion of the use of the chemical products utilized and of the condifions that interfere with their acfion during the disinfecfion process. The results obtained indicate the need for a standardization of the disinfection process as whole, according to current sanitary norms and for continuei in-service education in order to improve the quality of nursing care provided to the users of health services.

UNITERMS: Nebulizer disinfection. Disinfection routine in B.H.U. 